\title{
The Nasal Musculature as a Control Panel for Singing-Why Classical Singers Use a Special Facial Expression?
}

\section{Aura, Maarit}

2019-07

Aura, M , Geneid , A , Bjorkoy, K, Rantanen , M \& Laukkanen , A-M 2019 , ' The Nasal Musculature as a Control Panel for Singing-Why Classical Singers Use a Special Facial Expression?' , Journal of Voice , vol. 33 , no. 4 , pp. 510-515 . https://doi.org/10.1016/j.jvoice.2017.12.016

http://hdl.handle.net/10138/318817

https://doi.org/10.1016/j.jvoice.2017.12.016

publishedVersion

Downloaded from Helda, University of Helsinki institutional repository.

This is an electronic reprint of the original article.

This reprint may differ from the original in pagination and typographic detail.

Please cite the original version. 


\title{
The Nasal Musculature as a Control Panel for Singing-Why Classical Singers Use a Special Facial Expression?
}

\author{
*Maarit Aura, †Ahmed Geneid, †Kåre Bjørkøy, §Marita Rantanen, and *Anne-Maria Laukkanen, * $\S$ Tampere, and \\ $\dagger$ Helsinki, Finland, and $\ddagger$ Trondheim, Norway
}

\begin{abstract}
Summary: Objectives: This study aimed to explain the possible reason why classical singers seem to spread their nostrils and raise their cheeks before starting to sing.

Study Design: This is an experimental study.

Methods: Five subjects (three classical singers, two nonsingers) were investigated with nasofiberoscopy holding their breath after inhalation. The subjects were instructed to have a neutral expression first and then to take the singers' expression characterized by nostril flaring. In case of nonsingers, the special expression was rehearsed beforehand, guided by a classical singer. The following measurements were made: (1) height of soft palate, (2) area of the hypopharynx, (3) area of the epilaryngeal tube inlet (Aditus laryngis), and (4) dimensions of the (visible) glottis (length, width, and length-to-width ratio).

Results: All subjects raised the palate and widened the pharyngeal inlet, epilaryngeal inlet, and the glottis during "singer's expression."

Conclusions: The results suggest that classical singers may take advantage of breathing- and smelling-related connections between nasal and facial muscles and the larynx to avoid a hard glottal attack and pressed phonation and possibly also to assist the production of mixed register (head voice), characterized by a relatively low adduction between the vocal folds.
\end{abstract}

Key Words: Classical singing-Singer's expression-Nostril flaring-Nose wing breathing-Control of airway resistance.

\section{INTRODUCTION}

Classical singers seem to make special preparations before starting to sing. The preparations involve taking a good posture and deep inspiration, including lowering of the larynx and dropping of the lower jaw. Many singers also seem to spread their nostrils and raise their cheeks before singing.

Rubin et $\mathrm{al}^{1}$ stress that the necessity for proper posture has been recognized by singing teachers for centuries. However, it has taken the medical community (and the general public) longer to recognize its value. A good body posture facilitates well-balanced muscle function for breathing and laryngeal function, whereas a deviant body posture may be associated with laryngeal hypertension and voice disorders., ${ }^{2,3}$

Breathing strategy is generally regarded as an important factor in operatic singing. High consistency of lung volume behavior and of the rib cage control has been reported in classical operatic singers. ${ }^{4}$ The type of breathing has also been found to affect the voice source. Lowering of the diaphragm (in ordinary breathing at rest ca $1-3 \mathrm{~cm}$, and in deep inspiration up to $10 \mathrm{~cm}^{5}$ ) induces tracheal pull, which

\footnotetext{
Accepted for publication December 21, 2017.

From the " Speech and Voice Research Laboratory, University of Tampere, Tampere, Finland; †Department of Otolaryngology and Phoniatrics-Head and Neck Surgery, Helsinki University Hospital and University of Helsinki, Helsinki, Finland; $\ddagger$ Music Department, Norwegian University of Technology and Science, Trondheim, Norway; and the $\S$ Music School Pirkanmaan musiikkiopisto, Tampere, Finland.

Address correspondence and reprint requests to Maarit Aura, Speech and Voice Research Laboratory, University of Tampere, Åkerlundinkatu 5, 33100 Tampere,

Finland. E-mail: aura.maarit@gmail.com

Journal of Voice, Vol. 33, No. 4, pp. 510-515

0892-1997

(C) 2018 The Voice Foundation. Published by Elsevier B.V. All rights reserved.

https://doi.org/10.1016/j.jvoice.2017.12.016
}

reduces folding of the laryngeal tissues (ie, draws the vocal folds and false vocal folds apart) and also lengthens the vocal tract up to about $1 \mathrm{~cm} .{ }^{6}$ According to Iwarsson et al, ${ }^{7}$ the diaphragmatic activation tends to increase the peak amplitude of the flow glottogram, suggesting a change of phonation toward "flow phonation." Coactivation of the diaphragm may also stabilize the vocal tract and formant frequencies during pitch changes.

Articulation and vocal tract setting naturally affect resonance frequencies of the vocal tract. ${ }^{8}$ Lowering of the larynx, accompanied by narrowing of the epilaryngeal tube and widening of the pharynx, is known to be related to the establishment of the singer's formant cluster, which is essential for a classical male singer to be heard over the symphony orchestra. ${ }^{9,10}$ A similar cluster can be seen also in female singers at the lower pitch range. At higher frequencies, the female singers tend to adopt another technique. When the target pitch is higher than the first resonance (R1), female singers tend to tune the first resonance to a frequency near that of the fundamental (f0). The articulatory tool for this tuning mainly seems to be jaw opening: the wider the jaw opening, the higher the first resonance. ${ }^{11-13}$ Garnier et al ${ }^{14}$ discovered two different lip-opening strategies to achieve R1: f0 tuning. Some singers continuously increase lip opening with increasing pitch, whereas other singers increase it only over the highest part of the f0 range. Spreading of the lips as in smiling also raises the resonance frequencies. ${ }^{8}$

In addition to varying the degree of jaw and mouth opening and spreading or protruding the lips, which obviously alter the resonances, the singers tend to use a special facial 

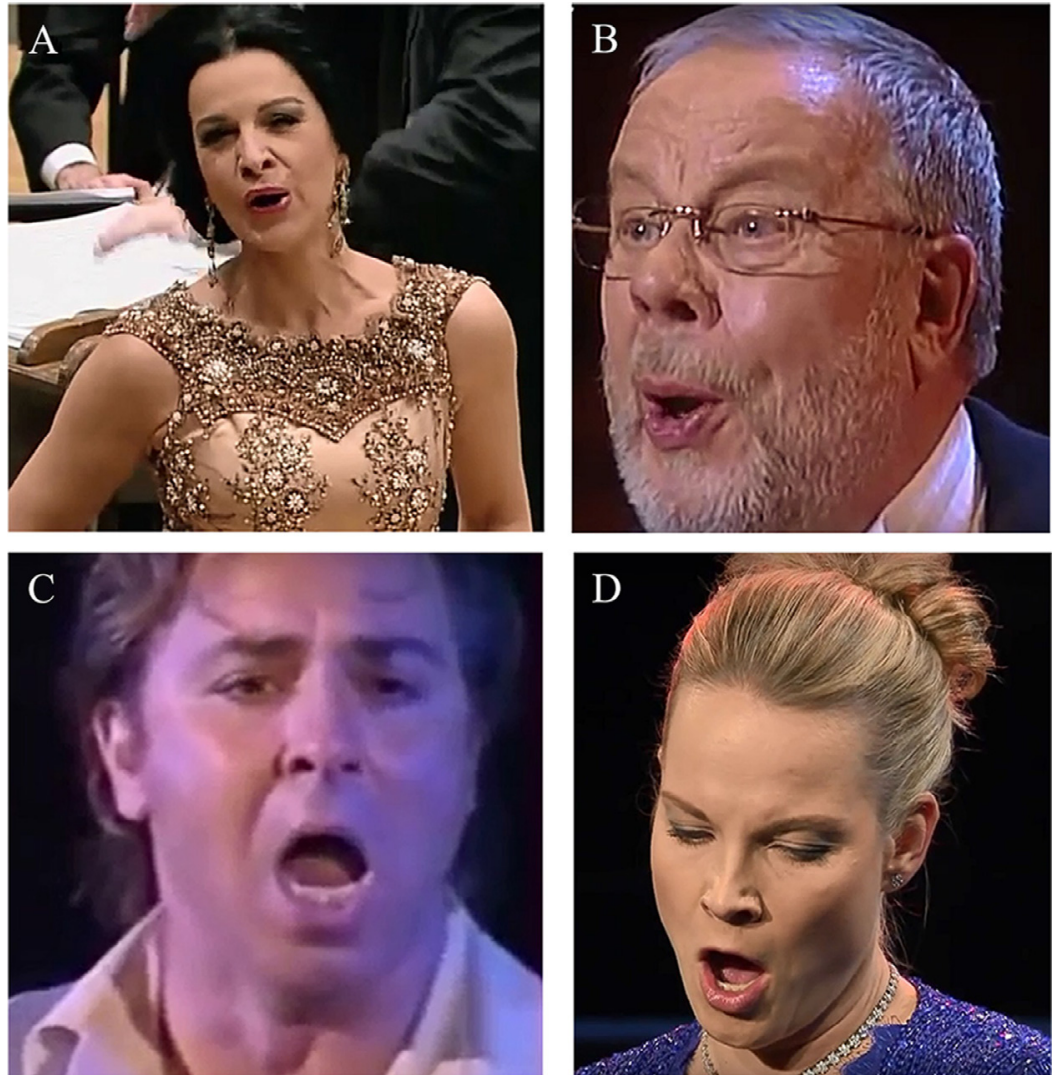

FIGURE 1. A. Soprano Angela Georghiu. B. Bass Matti Salminen. C. Tenor Roberto Alagna. D. Mezzo-soprano Elīna Garanča.Source: www.youtube.com.

expression which does not seem to depend on gender, voice classification, pitch, vowel, or conveyance of emotions. This facial expression with particular flaring of the nostrils and raising of the cheeks can be seen before starting to sing and throughout singing (Figure 1). This expression can be observed frequently when watching professional classical singers on stage and in the videos and photos taken of world-famous operatic singers while singing. According to Miller, "This slight elevation of the zygomatic musculature is commonly observed among major singing artists who adhere to the international school of resonance balancing." 15 A special facial expression is taught by many song pedagogues. ${ }^{16}$ They use instructions such as "open up the upper hall for head resonance" or "smell the scent of a flower/if something is burning here" or "think of the beginning of yawning", or "think of a bad smell/something disgusting" or "use an inner smile" (see for example Stone ${ }^{17}$ ) when they apparently try to urge this kind of involvement of facial muscles in the preparation. The instruction "sing into the mask," that is, when it feels that you have an extra layer like a mask over your face and your voice lies between your face and the mask, also seems to be related to the special facial expression.

Many pedagogues have linked all facial expressions to voice quality through resonances. In his book Solutions for Singers: Tools for Performers and Teachers, Miller reasons how zygomatic muscles affect singing by altering the shape of the vocal tract and thereby the vocal timbre. ${ }^{15} \mathrm{He}$ discusses the importance of the zygomatic muscles as they relate to resonance balancing. "When a pleasant expression (not a smile) accompanies complete inspiration, prior to velopharyngeal closure, the velum rises slightly, changing the shape of the resonator tract in the velopharyngeal area." ${ }^{15}$ Miller also writes that a typical French singer seems to raise the upper maxillary area, including the cheeks, nearly as one does in laughter. ${ }^{18}$ Some spectrographic observations have been made on the effects of singer's expression on the voice, ${ }^{16}$ but on the basis of mere acoustic output, it is naturally not possible to draw conclusions of what exactly changes inside a singer during a facial expression.

Even though the singer's expression may be a part of a larger preparation including deepening of the inspiration, lowering of the larynx and thus increasing the pharyngeal volume, and perhaps an increase in the overall state of alertness (see for example Theorell ${ }^{19}$ ), the present study focuses on the role of the facial expression per se. The main muscle responsible for the singer's expression seems to be the alar part of the nasal muscle, musculus nasalis, which is the largest of the nasal muscles. It has two parts with opposing functions. The transverse part compresses the nares, and the alar part opens the nares, thus causing flaring of the nose. Procerus muscle between the eyebrows helps to open the nostrils. Another muscle that may play a role in the singer's expression is levator labii superioris alaeque nasi, lifter of the upper 


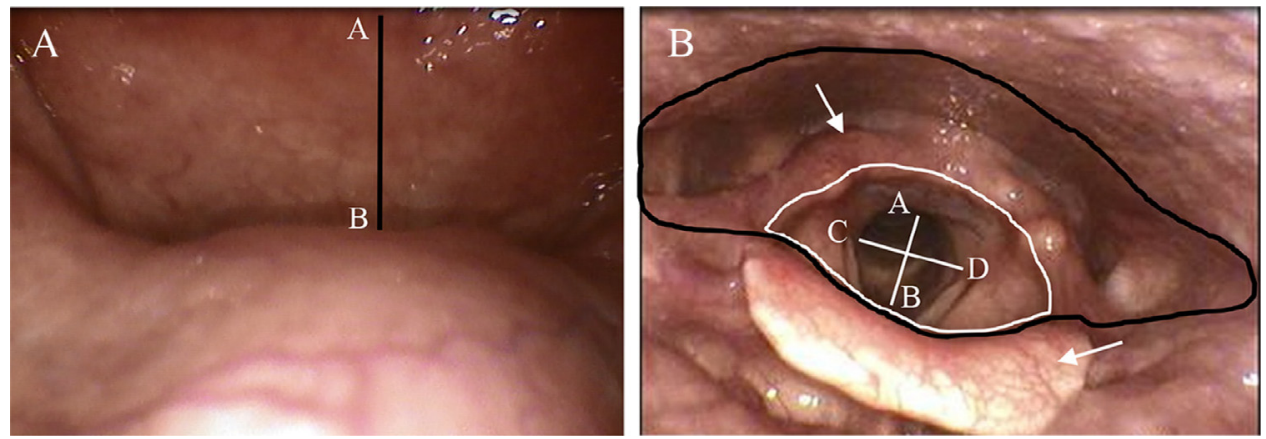

FIGURE 2. A. Distance from the roof of the nasopharynx, point A, to the soft palate, point B (black line). B. Area of the pharyngeal inlet (black line), area of the epilaryngeal inlet (white line), and length and width of the (visible) prephonatory glottis (white cross). The measurements of the areas (in pixels) were accomplished for the spaces that are surrounded by black or white lines. Glottal length and width were measured as distances from point $\mathrm{A}$ to point $\mathrm{B}$, and from point $\mathrm{C}$ to point $\mathrm{D}$, respectively. Lower black arrow points to epiglottis and upper arrow points to (right) arytenoid cartilage.

lip and of the wing of the nose, which may give the face a somewhat scornful expression, as in disgust. Yet another muscle, zygomaticus minor muscle (musculus zygomaticus minor) may assist in raising the cheeks, without necessarily causing a smile-related shaping of the mouth. ${ }^{20}$

In this study, we aim to answer two questions:

(1) Does something change in the nasopharynx, hypopharynx, and larynx of classical singers when they, without singing, take the singer's expression with flaring of the nostrils?

(2) Do the same possible effects on the vocal tract occur also in nonsingers when they imitate this posture?

\section{Participants and tasks}

Five volunteers with a healthy larynx participated in the study. Three volunteers (one male, two female) were trained professional classical singers (age 37-70) with at least 10 years of professional training and $10-40$ years of experience in professional operatic singing and teaching of classical singing. The other two were nonsingers (a 55-year-old woman with some occasional classical singing training in total for about 3 years, and a 38-year-old man with no singing training at all). The nonsinger subjects were first shown how a singer's expression looks like, and then imitated and rehearsed it for 1-2 minutes, guided by a professional classical singer. The participants were instructed first to take a deep breath like before starting to sing and hold it, and then to take the singer's expression. In this way, we aimed to eliminate all possible breathing-related changes in, for example, laryngeal position.

\section{Nasofiberoscopy}

The subjects were scoped in sitting position. Nasofiberoscopic registrations were made by an experienced otorhinolaryngologist/phoniatrician using an endoscope (ORL Vision RS1, CCD supplied by Rehder \& Partners, Hamburg, Germany). The tasks were repeated so that first the scope was in the nasopharynx, and then so that the scope was inserted in the pharynx. The position of the scope was carefully held the same in both tasks by monitoring the view on a screen. Topical anesthesia was used if needed. All participants tolerated the experiment well.

\section{Analyses}

\section{Measurements of vocal tract dimensions}

The nasoendoscopic images were analyzed as follows. (1) The positioning of the soft palate (velum) was studied by measuring the distance from the highest part of the velum to the roof of the nasal cavity (Figure 2A). (2) The areas of the pharyngeal inlet, the epilaryngeal inlet (Aditus laryngis), and the dimensions of the (visible) prephonatory glottis (length and width, and length-to-width ratio) were measured (Figure 2B). The area of the epilaryngeal inlet is the space surrounded by the epiglottis in the front, arytenoid cartilages in the back, and the ary-epiglottic folds at the sides. ImageJ software (Java8, 64 bits, ImageJ 1.42q Wayne Raspand, National Institutes of Health, USA) was used in the measurements. The distances and areas were measured only qualitatively (in pixels) because no calibration was possible. However, the camera was carefully kept at the same position for both types of samples (ie, without and with the singer's expression) that were produced in a row. Measurements were made independently by two researchers to evaluate the measurement accuracy.

\section{RESULTS}

There was a good correlation between the measurements of the two researchers (Spearman's rho: $\mathrm{r}$ 0.85-0.98, P 0.007 -0.021 .)

The results show (Table 1, Figures 3-4) that the velum rose, and the pharyngeal and epilaryngeal inlet and the glottis widened when the subjects took a singer's facial expression. For subject A (the trained male), the permanently narrow epilaryngeal inlet made it impossible to measure the glottal distances. The size and position of the steady structures did not vary much between the pairs of figures to be 
TABLE 1.

Results for Measurements of the Nasopharynx (Height of Velum), Pharynx (Area of the Pharyngeal Inlet), Epilarynx (Area of the Epilaryngeal Inlet), and the Glottis (Length and Width) in Pixels

\begin{tabular}{|c|c|c|c|}
\hline & $\begin{array}{c}\text { After } \\
\text { Inhalation }\end{array}$ & $\begin{array}{c}\text { With } \\
\text { Nostril } \\
\text { Flaring }\end{array}$ & $\begin{array}{c}\text { Difference } \\
(\%)\end{array}$ \\
\hline \multicolumn{4}{|l|}{ Nasopharynx } \\
\hline Subject A (male) & 1,152 & 872 & -24.3 \\
\hline Subject B & 1,512 & 1,170 & -22.6 \\
\hline Subject C & 98.8 & 93 & -5.8 \\
\hline Subject D (nonsinger) & 1,004 & 800 & -20.3 \\
\hline $\begin{array}{l}\text { Subject } E \text { (male } \\
\text { nonsinger) }\end{array}$ & 2,722 & 2,068 & -24 \\
\hline \multicolumn{4}{|l|}{ Pharynx } \\
\hline Subject A & 23,1367 & 297,900 & 28.8 \\
\hline Subject B & 235,7101 & 290,1650 & 23.1 \\
\hline Subject C & 253,3190 & 339,1584 & 33.9 \\
\hline Subject D & 375,547 & 461,933 & 23 \\
\hline Subject E & 74,974 & 98,983 & 32 \\
\hline \multicolumn{4}{|l|}{ Epilarynx } \\
\hline Subject $A$ & 26,710 & 33,336 & 24.8 \\
\hline Subject B & 432,576 & 75,4669 & 74.5 \\
\hline Subject C & 460,084 & 91,7575 & 99.4 \\
\hline Subject D & 80,203 & 18,5036 & 130.7 \\
\hline Subject E & 26,368 & 26,590 & 0.8 \\
\hline \multicolumn{4}{|l|}{ Pharynx/Epilarynx } \\
\hline Subject $A$ & 8.7 & 8.9 & 3.2 \\
\hline Subject B & 5.4 & 3.8 & -29.4 \\
\hline Subject C & 5.5 & 3.7 & -32.9 \\
\hline Subject D & 4.7 & 2.5 & -46.7 \\
\hline Subject E & 2.8 & 3.7 & 30.9 \\
\hline \multicolumn{4}{|l|}{ Glottal length } \\
\hline \multicolumn{4}{|l|}{ Subject $A$} \\
\hline Subject B & 150 & 548.5 & 265.7 \\
\hline Subject C & 522.4 & 454.2 & -13.1 \\
\hline Subject D & 240 & 290 & 20.8 \\
\hline Subject E & 509 & 492 & -3.3 \\
\hline \multicolumn{4}{|l|}{ Glottal width } \\
\hline \multicolumn{4}{|l|}{ Subject A } \\
\hline Subject B & 120.3 & 573.2 & 376.3 \\
\hline Subject C & 329.3 & 611.6 & 85.7 \\
\hline Subject D & 66.9 & 196 & 192.9 \\
\hline Subject E & 355 & 549 & 54.6 \\
\hline \multicolumn{4}{|l|}{ Length-to-width ratio } \\
\hline \multicolumn{4}{|l|}{ Subject $A$} \\
\hline Subject B & 1.2 & 1 & -23.2 \\
\hline Subject C & 1.6 & 0.7 & -53.2 \\
\hline Subject D & 3.6 & 1.5 & -58.7 \\
\hline Subject E & 1.4 & 0.9 & -37.5 \\
\hline
\end{tabular}

Notes: Changes are presented in percentage.

compared (ie, one for without expression and one with expression). Therefore, it can be concluded that the distance between the camera and the objects of study remained sufficiently stable. The length-to-width ratio of the glottis decreased in all subjects, confirming that the glottis widened, which is obvious also by looking at the images. The ratio calculated between the pharyngeal and the epilaryngeal areas shows that in most cases the epilaryngeal area increased relatively more than the pharyngeal area, especially in the trained singers (Table 1).

\section{DISCUSSION}

Even though the singer's expression may be a part of a larger preparation, including deepening of the inspiration, lowering of the larynx, and thus increasing the pharyngeal volume, the main reason for exploiting a singer's expression per se does not seem to be to change the shape and size of mouth opening and thus to affect the vocal tract resonances, but rather to take advantage of the connection between nasal and facial muscles and the larynx. We compared the nasopharyngeal, pharyngeal, and glottal measures before the singers started to sing without facial expression with those measures that were observed with the expression. The results showed that the singer's facial expression resulted in lifting of the velum and widening of the hypopharynx, epilarynx, and the glottis also when recruited without any other changes, for example, in breathing. These pure facial maneuvers seem to be related to inhalatory- and smellingrelated reflexive muscle functions.

Flaring of the nostrils is known to improve breathing by widening the glottis involuntarily. So-called nose wing breathing (Nasenflügelatmung) has been listed as one of the symptoms seen in patients with difficulties in breathing. Voluntary flaring of the nostrils has been documented in the clinical tips that aid in examining the movement of the vocal folds. It is reported among different other tips in an upcoming phoniatrics textbook. ${ }^{21}$ Patients with vocal cord dysfunction usually also report ease of attacks when shifting the breathing from through the mouth to through the nose, which opens the glottis more. Furthermore, it is interesting to note that flaring of the nostrils has been reported as a common associated gesture in patients with abductor spasmodic dysphonia. ${ }^{22}$ This can be explained by the fact that nasal muscles have a relation to respiratory muscles. The nuclei controlling these muscles are located close to each other in the brain stem (see for example Kratschmer ${ }^{23}$ ).

As related to singing, widening of the glottis (before the phonation starts) may not only assist a quick air intake but also establish a gentle adduction, which helps to avoid hard glottal attack and pressed phonation. ${ }^{24}$ Therewith the collision between the vocal folds during phonation, and thus the mechanic load on the vocal fold tissue decreases. ${ }^{25}$ When the vocal folds are barely adducted before onset of phonation, it favors the so-called resonant phonation or flow phonation, ${ }^{24,26}$ which has been regarded as optimum. Furthermore, a wider prephonatory glottis possibly also assists in the production of mixed register (head voice), characterized by a relatively low adduction between the vocal folds. ${ }^{27}$ It is possible that raising the velum may also cause some vertical stretching on the vocal fold tissue, which could be helpful for mixed register phonation. Together 


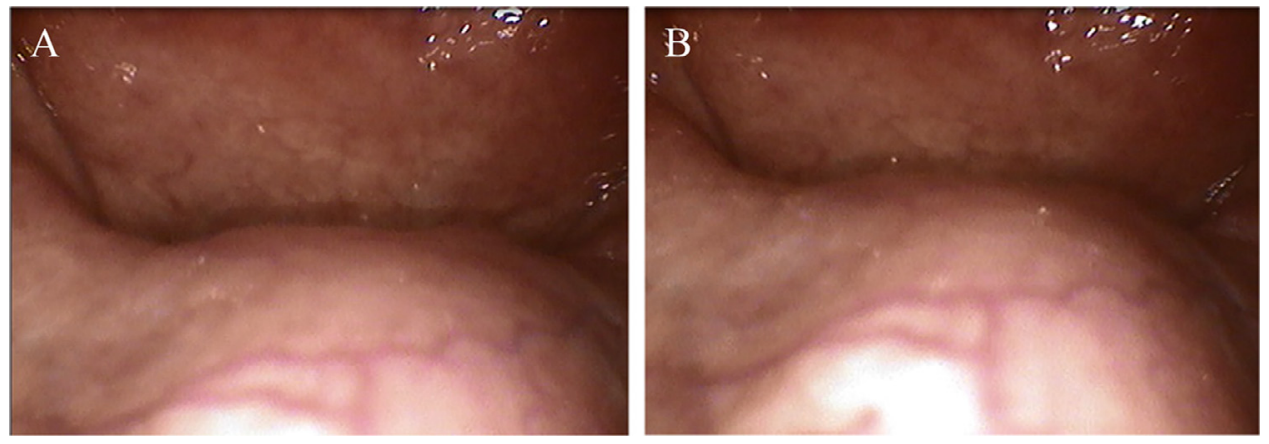

FIGURE 3. Height of the velum (A) after normal inhalation and (B) during flaring of the nostrils.
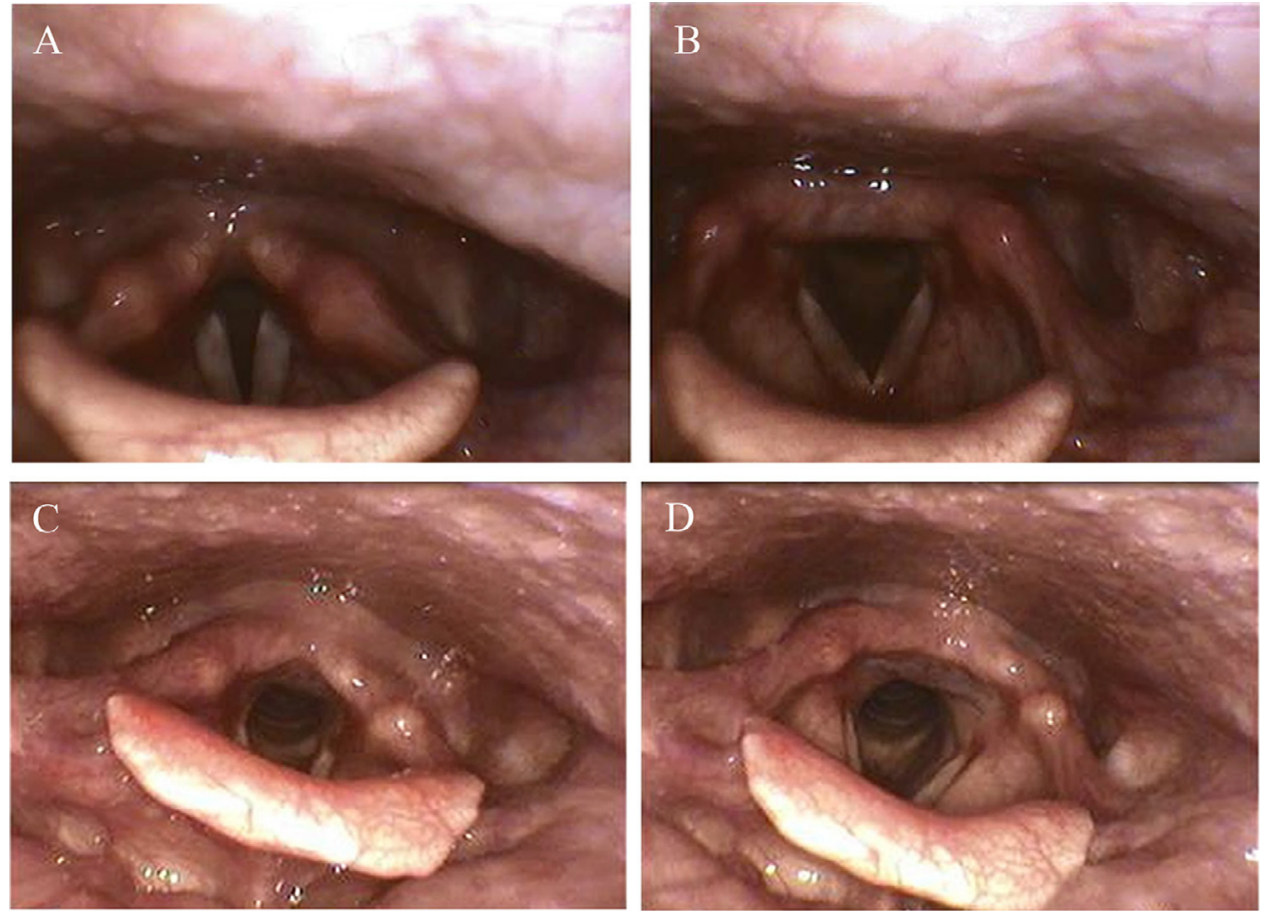

FIGURE 4. Pharyngeal, epilaryngeal and glottal dimensions for subject $\mathbf{C}(\mathbf{A}$ and $\mathbf{B})$ and for subject $\mathbf{B}(\mathbf{C}$ and $\mathbf{D})$ : after normal inhalation (A and C): during flaring of the nostrils (B and D).

with an adequate vocal tract setting, the gentle glottal adduction may increase acoustic-mechanic interaction between the vocal folds and supra- and subglottal resonances. The increase in acoustic-mechanic interaction would allow lower phonation threshold pressure and wider amplitude of the vocal fold vibration without excessive collision, and thus improve effective and economic vocal fold vibration. $^{28}$

Widening of the pharynx (eg, by lowering the larynx, by relaxing the pharyngeal constrictors, and, to some extent, by raising the velum) and narrowing of the epilarynx may be seen beneficial to establish the singer's formant. ${ }^{9,10}$ Narrowing of the epilaryngeal tube has been documented in classical singers. ${ }^{28,29}$ A widening of the epilaryngeal inlet, which was seen in the present study, may be explained by the fact that we documented the situation just before onset of phonation not during it. It is possible that the singer's expression, which remains throughout singing, helps the singer to control the three sphincters of the larynx ${ }^{29}$ separately, that is, to keep the adduction gentle and at the same time narrowing the epilarynx.

The results of the present study suggest that flaring of the nostrils may be a useful concrete tool in voice and speech training and voice therapy to promote soft voice onset and to avoid or reduce vocal hyperfunction.

\section{REFERENCES}

1. Rubin JS, Mathieson L, Blake E. Posture and voice. J Sing. 2004:271275 .

2. Kooijman PGC, de Jong FICRS, Oudes MJ, et al. Muscular tension and body posture in relation to voice handicap and voice quality in teachers with persistent voice complaints. Folia Phoniatr Logop. 2005; $57: 134-147$.

3. Zenker W, Zenker A. Uber die Regelung der Stimmlippenspannung durch von aussen eingreifende. Mechanismen. 1960;12:1-36.

4. Thomasson M, Sundberg J. Consistency of phonatory breathing patterns in professional operatic singers. J Voice. 1999;13:529-541.

5. Zemlin WR. Speech and Hearing Science. Anatomy and Physiology. 2nd ed. Englewood Cliffs, NJ: Prentice-Hall Inc.; 1981. 
6. Zenker W, Glaninger J. Die Stärke des Trachealzuges beim lebenden Menschen und seine Bedeutung fur die Kehlkopfmechanic. Z Biol. 1959;111:154-166.

7. Iwarsson J, Thomasson M, Sundberg J. Effects of lung volume on the glottal voice source. $J$ Voice. 1998;12:424-433.

8. Fant G. Acoustic Theory of Speech Production. The Hague: Mouton; 1960.

9. Sundberg J. Articulatory interpretation of the singing formant. $J$ Acoust Soc Am. 1974;55:838-844.

10. Titze I, Story B. Acoustic interactions of the voice source with the lower vocal tract. J Acoust Soc Am. 1997;101:2234-2243.

11. Sundberg J. What's so special about singers. J Voice. 1990;4:107-119.

12. Sundberg J. Formant technique in a professional female singer. Acustica. 1975;32:89-96.

13. Rothenberg M. Cosí fan tutte and what it means or nonlinear sourcetract acoustic interaction in the soprano voice and some implications for the definition of vocal efficiency. In: Baer T, Sasaki C, Harris KS, eds. Vocal Fold Physiology: Laryngeal Function in Phonation and Respiration. San Diego: College-Hill Press; 1986.

14. Garnier M, Henrich N, Smith J, et al. Vocal Tract Adjustments in the High Soprano Range. Voice Foundation, Philadelphia, Pennsylvania, USA: Acoustical Society of America; 2010:37713780.

15. Miller R. Solutions for Singers: Tools for Performers and Teachers. New York: Oxford University Press; 2004.

16. McQuade JH. The effect of the position of the zygomatic musculature of the experienced baritone singer on the voice spectra. $J$ Singing. 2016;72:441-449.

17. Stone JB. You Can Sing. New York: Amsco Publications; 1995.
18. Miller R. English, French, German and Italian Techniques of Singing. Lanham, Maryland, USA: Scarecrow Press; 1977.

19. Theorell T. Noter Om Musik Och Hälsa. Stockholm: Karolinska Institutet University Press; 2009.

20. Schuenke M, Schulte E, Schumacher U, et al. Head, Neck and Neuroanatomy. Atlas of Anatomy, Vol. 3. Stuttgart, Germany: Thieme Medical Publishers; 2016.

21. Geneid A. Tips and tricks for laryngeal examination. In: am ZehnhoffDinnesen A, Wiskirska-Woznica B, Neumann K, Nawka T, Eds. European Manual of Phoniatrics 1. Springer; 2019. Available at: http://www. springer.com/us/book/9783662467794.

22. Menon JR. Flaring of ALA Nasi: A reliable diagnostic sign for abductor spasmodic dysphonia. Int J Phonosurgery Laryngol. 2011;1:41-43.

23. Kratschmer F. On reflexes from the nasal mucous membrane on respiration and circulation. Respir Physiol. 2001;127:93-104.

24. Verdolini K, Druker DG, Palmer PM, et al. Laryngeal adduction in resonant voice. $J$ Voice. 1998;12:315-327.

25. Jiang JJ, Titze IR. Measurement of vocal fold intraglottal pressure and impact stress. J Voice. 1994;8:132-144.

26. Sundberg J. Vocal fold vibration patterns and phonatory modes. STLQPSR. 1994;35:2-3.

27. Titze IR. Bi-stable vocal fold adduction: a mechanism of modal-falsetto register shifts and mixed registration. $J$ Acoust Soc Am. 2014;135:2091-2101.

28. Kmucha ST, Yanagisawa E, Estill J. Endolaryngeal changes during high-intensity phonation: videolaryngoscopic observations. $J$ Voice. 1990;4:346-354

29. Cookman S, deVore K. Inside the Singing Voice, Laryngeal Teaching Series. Vol. 4. Chicago: Total Voice Inc; 2006. 